\title{
LA MATERIA DEL CANTO: POESÍA Y CANCIÓN EN JOSÉ AGUSTÍN GOYTISOLO*
}

\section{THE MATTER OF SINGING: POETRY AND SONG IN JOSÉ AGUSTÍN GOYTISOLO}

\author{
María Payeras Grau \\ Universitat de les Illes Balears
}

RESUMEN: Este artículo estudia la estrecha relación entre la poesía de José Agustín Goytisolo y la canción, lo que conduce a la identificación práctica de ambos conceptos en su obra. Por otra parte, se enfoca la atención en los aspectos intertextuales que se aprecian entre la obra goytisoliana y la canción tradicional y popular.

Palabras clave: Poesía del medio siglo; canción; José Agustín Goytisolo; intertextualidad.

AвSTRACT: This article studies the close relationship between the poetry of José Agustín Goytisolo and the song, which leads to the practical identification of both concepts in his work. It also explores the intertextual aspects of Goytisolo's work with the traditional and popular song.

KEY wORDS: 1950s poetry; song; José Agustín Goytisolo; intertextuality.

Este artículo se halla vinculado al Proyecto de Investigación del Plan Estatal «Poéticas de la Transición (1973-1982)», financiado por: FEDER/Ministerio de Ciencia, Innovación y Universidades - Agencia Estatal de Investigación/ FFI2017-84759-P. 
La temática enunciada en el título de este trabajo puede abordarse desde dos líneas fundamentales. Una de ellas, del todo pertinente, consiste en estudiar la difusión musicada de los poemas del autor. La otra línea consiste en explorar los aspectos musicales de la poesía goytisoliana, que son muchos y pueden ser revisados desde múltiples perspectivas.

En relación a la primera línea, quiero señalar el encomiable trabajo de José C. Cárdenas en el blog «Música y poesía», que, desde el 28 de enero de 2017, ha sistematizado en seis entradas la relación de Goytisolo con la música, recogiendo los poemas que tiene registrados en el repertorio de la SGAE y las grabaciones musicales de sus poemas, empezando por los que divulgó el grupo turinés Cantacronache con el título Canción de paz, que Goytisolo incluiría en su colección Del tiempo y del olvido (1977) con el título «Soldado sí». De acuerdo con la información suministrada por Cárdenas, los poemas de este autor han sido musicados o cantados, entre otros, por Jesús Munárriz, Patxi Andión, Paco Ibáñez, Massiel, José Manuel Herraiz, Ángel Parra, Rosa León, Veneno, Mercedes Sosa, Liliana Herrero, etc. (Cárdenas, 2017a, 2017b, 2017c, 2017d, 2017e, 2017f: en línea). Es obvio, por lo tanto, que la poesía goytisoliana ha llamado la atención de músicos reconocidos de distintos países y, por ello, la música ha sido para ella un mecanismo de difusión nada desdeñable.

En relación a la segunda línea antes apuntada, es un hecho que la poesía, como género literario, posee una evidente correlación con la música. Étienne Souriau, en La correspondance des arts, habla de la casi-complementariedad de las artes literarias y musicales. Ambas disciplinas comparten una base rítmica, lo que les proporciona un origen común. Pero Souriau insiste en que los paralelismos no supeditan una de estas artes a la otra. Contrariamente, su parecer es que «la musique et le poème ici se correspondent, non par calque de l'un sur l'autre, mais comme faisant écho à un même univers que l'une et l'autre posent» (Souriau, 1969: 165). Esta correlación innegable ha sido la base de innumerables estudios literarios, particularmente de aquellos que se ocupan de aspectos rítmicos, que son el engarce natural entre ambas disciplinas artísticas. En palabras de Eustaquio Barjau,

[e]n el verso el lenguaje "cursa» de un modo cíclico; el oyente, o el lector, que es algo así como un autooyente silencioso, va oyendo lo que ya esperaba oír: acentos que se esperan y 
llegan, unidades silábicas que se van presentando en los momentos en los que se las esperaba. La distinción tradicional entre ritmo y rima, herencia tal vez de las curiosas «preceptivas literarias» - el nombre ya lo dice todo- es una distinción carente de sentido: ambos recursos, los acentos y la repetición de unidades silábicas, pertenecen al ritmo, porque ritmo es recurrencia (2009: 46).

En el caso de José Agustín Goytisolo, las correspondencias musicales abarcan un amplio espectro, siendo esencial su correspondencia con la canción, tanto en el sentido antes mencionado — es decir, la difusión masiva de sus poemas musicados por cantautores-, como en el sentido de las fuentes musicales que el poeta absorbe y traslada a su obra. Además, y de forma relevante, la teoría metapoética del autor incide continuamente en asociar los conceptos de poema y canción, binomio que, en la tradición hispánica, se vincula tanto a tradiciones cultas como populares, siendo las segundas las que arraigan más en su pensamiento.

Cuando José Agustín Goytisolo se interroga acerca de la naturaleza de la poesía, se deslizan sobre sus versos conceptos que resaltan su afinidad con la música, presentándola como palabra cantada. En este sentido, es revelador su «Oficio de poeta» (2009: 145) ${ }^{1}$, de Algo sucede (1968). En relación a este poema quiero llamar la atención sobre tres elementos en los que, de forma recurrente, Goytisolo hace descansar su idea de la poesía: la artesanía, la memoria y el canto. El quehacer artesano se asocia al oficio poético por dos motivos fundamentales: de una parte, establece un patrón igualitario entre autor y lector que se contrapone a la idea del artista como ser superior; de otra, insiste en la capacidad de crear poesía como un dominio adquirido mediante la práctica y el esfuerzo, alejándolo igualmente de la idea tradicional de la inspiración, como rapto reservado al genio: «Contemplar las palabras / sobre el papel escritas: / medirlas, sopesar / su cuerpo en el conjunto /del poema. / Y después / -igual que un artesano- / separarse a mirar / cómo la luz emerge / de la sutil textura».

En lo que respecta a la memoria, es, de forma innegable, uno de los elementos esenciales de la poética goytisoliana, en las dos

1 Aunque aparezca la mención del poemario donde se incluyen los poemas citados en este artículo, las menciones de página corresponden siempre a la Poesía completa editada por Carme Riera y Ramón García Mateos (2009). 
vertientes que él mismo apunta en la segunda secuencia estrófica:la memoria individual y la memoria colectiva. Ambas vertientes están muy presentes en su obra y en las de otros poetas de su generación, convirtiéndose en el venero principal de la corriente elegíaca que alimenta, desde el origen, su poética. En este punto, vale la pena recalar en una de las principales variantes que ofrece el poema en su versión de 1996 respecto a la de 1968. En su primera versión, el poema hablaba de desempolvar «la historia, los deseos, / las pasiones del hombre», mientras que en la segunda menciona «la historia y los deseos / de mujeres y hombres». Goytisolo corrige así su propia visión androcéntrica de la realidad, revelando una adquirida conciencia de la realidad social de las mujeres, que ellas mismas, con la fuerza de una movilización que fue intensificándose desde el inicio de la Transición, habían ido visibilizando.

Finalmente, la tercera estrofa es la que vincula la poesía al canto, y también aquí son muy significativos los cambios que se producen en la segunda versión del poema.Veamos las dos versiones:

La materia del canto
nos la ha ofrecido el pueblo
con su voz. Devolvamos
las palabras reunidas
a su auténtico dueño.
La materia del canto
nos la ofrecen las hablas
con su voz. Devolvamos
las palabras reunidas
a sus dueños auténticos ${ }^{2}$.

En 1968, la situación española, todavía bajo el yugo de la dictadura, lleva a Goytisolo a poner el acento en el colectivo de la ciudadanía - elusivamente mencionada como «pueblo» cuando los derechos ciudadanos son sistemáticamente vulnerados—- asimilando la voz del poeta a la de ese colectivo. En el fondo, subyace todavía la idea del poeta como altavoz de los anhelos de una ciudadanía que no sabe o no puede expresarse por sí misma. En la versión posterior, desaparecen las reminiscencias de la voz popular como unidad para reflejar una imagen de colectividad plural, donde cada ciudadano se expresa con una voz individual. En este sentido, el poeta se refiere

2 Los subrayados son míos. 
a las «hablas», un concepto con obvias reminiscencias de la lingüística saussureana, que contempla la «lengua» como una abstracción y el «habla» como la concreción individual de la lengua. Las hablas reflejan, pues, la pluralidad de las voces, sentimientos, ideas, etc., que el autor recoge en su obra.

Estos tres aspectos se agrupan en torno a un elemento central en el pensamiento del autor, que consiste en vincular su ars poética al colectivo humano y sus necesidades. En su concepto, la poesía no puede ni debe ser un arte solipsista, de ahí que sea tan importante la transmisibilidad de la misma y su asimilación por parte de un público extenso, entendiendo que las capas populares de la población son el alfa y el omega de la poesía: su origen y su destino.

Pero lo que «La materia del canto» evidencia desde el propio título es la cercanía entre poema y canción que existe en el pensamiento metapoético goytisoliano. No por azar, uno de los recopilatorios de su poesía lleva por título Palabras para Julia y otras canciones (1980). Hasta tal punto se produce la simbiosis conceptual entre ambos términos, que estos se utilizan frecuentemente como sinónimos a lo largo de toda su obra.

Este principio rector hará ineludible la consideración de las relaciones entre la poesía de Goytisolo y distintas formas de canción que están presentes en su obra: entre otras, la lírica tradicional, que no solo se aprecia en el plano de la intertextualidad, sino que se inscribe de lleno en el plano metapoético. En este sentido sería interesante reparar en «El poema, no yo» (Goytisolo, 2009: 737): «Hay quien lee y quien canta poemas que yo hice / y quien piensa que soy un escritor notable. / Prefiero que recuerden algunos de mis versos / y que olviden mi nombre. Los poemas son mi orgullo».

Como elemento asociado a la lírica tradicional, se advierte aquí un eco del sistema literario medieval en lo que respecta a la autoría de la obra y su difusión. Me refiero al binomio formado por el trovador y el juglar, del que advertimos un paralelo en el binomio poeta-cantante (o, en algunos casos, cantautor), característico del sistema musical popular español más o menos desde la década de los 60. Este binomio está implícito en «El poema: no yo», de 1995, y en «Una revelación», de Como los trenes de la noche (1994). En el primero es muy claro el reconocimiento del autor hacia aquellos que han musicado y difundido su obra a través de la canción, porque le facilitan el privilegio de convertirse en "poeta anónimo». El hecho 
de que sus palabras tengan la fuerza suficiente como para mantenerse vivas en la memoria y las emociones del colectivo al que van destinadas, por encima del recuerdo de quien las compuso, representa para Goytisolo el mayor honor imaginable. La paradójica vanidad de diluir su identidad para que se absorba en la memoria colectiva dice mucho acerca de la subordinación del ego y la vanidad propia del creador a principios y valores que ponen en alza las necesidades colectivas a las que se han de supeditar las individuales. En este sentido, «Una revelación» (Goytisolo, 2009: 723) explora justamente la relación entre el creador y el colectivo al que su obra se destina, desarrollando un sentido comunitario de la poesía que menosprecia la expresión de experiencias personales elogiando, en cambio, la capacidad de reflejar los sentimientos y las emociones donde otros puedan identificarse. La escritura no tiene sentido como desahogo personal, sino únicamente como comunicación privilegiada entre autor y lector, incluso si el autor permanece en el anonimato. En alguna medida este pensamiento arraiga en la ideología del poeta y se asocia al sentido revolucionario de su obra, ya que, tal como dice en Como los trenes de la noche (1994), «cantar alto» frente al oponente ideológico «será siempre una rebelión» (Goytisolo, 2009: 719). No hace falta decir que la rebelión de Goytisolo, su insumisión frente al poder, es un hecho histórico y no una entelequia. Asimismo cabe recordar que sus poemas no solo fueron publicados en forma de libro, sino también divulgados en recitales más o menos clandestinos, en fábricas y universidades, contribuyendo a la difusión de una ideología contraria a la dictadura:

cuando José Agustín recitaba en las aulas de las universidades
lo hacía casi a escondidas, introducido por las puertas tra-
seras, rodeado del recelo de bedeles y decanos digitarios y
simplemente respaldado por la minoría de estudiantes que
en los años cincuenta y sesenta créan, firmemente creíamos
que la poesía era un arma de combate (Vázquez Montalbán,
1980: 6).

La subordinación del poeta a su obra y de esta al colectivo a quien va destinada tiene también su reflejo en el homenaje realizado a otros autores, como León Felipe y Catulo.

«La voz y el viento de León Felipe» (Goytisolo, 2009: 667), de El ángel verde y otros poemas, es un homenaje al poeta exiliado donde salen a relucir temas centrales de la poética goytisoliana como la 
legitimación de la escritura en su propio carácter reivindicativo, la vinculación de la palabra del poeta a la voz colectiva de la ciudadanía, la relación de la poesía culta con el venero lírico popular y el meollo elegíaco que sustenta la voz del poeta.

La apoyatura bíblica que hay en la poesía de León Felipe tiene su réplica en los Salmos al viento de Goytisolo y ambos cuajan en una obra reivindicativa. Pero el elemento que quiero resaltar de forma especial en este poema es el que se desprende de los siguientes versos: «ya que todo lo tuyo te lo habían robado / pero no la canción». Obviamente, hay una alusión a los conocidos versos de León Felipe en su "Canción del poeta vagabundo», de Ganarás la luz (León Felipe, 2006 [1943]: 112): el poema, de todos conocido, en el que habla de dos Españas irreconciliables, la cainita y la del desarraigo forzoso. Injustamente, como el propio León Felipe reconocería años después en carta a Ángela Figuera ${ }^{3}$, el poema pretende que, en el desigual reparto patrimonial que les ha correspondido a las Españas en liza, la España desterrada se ha quedado con la canción, lo que también para el poeta de Tábara se asimila a la palabra poética.

Goytisolo y León Felipe coinciden en la idea de que el patrimonio del poeta es inmaterial, reside en su voz y en la capacidad de propagación de la misma. Para el primero, su máxima riqueza es, paradójicamente, la desposesión de todo lo suyo, incluida su obra. Esta misma idea la desarrolla nuevamente — ahora con intención satírica - en «Sobre un poema de Catulo» (Goytisolo, 2009: 669), un texto que ridiculiza a sus adversarios artísticos, utilizando nombres en clave y situándolos en un parnaso vicario y sucedáneo, reafirmándose en la prevalencia de la obra por encima del creador.

Una vez establecida la asunción de la anonimia como destino de la obra y su asimilación como cosa propia en el venero popular, la lógica interna de la poesía goytisoliana conduce al diálogo con la lírica tradicional, poniendo en evidencia un arraigo que ha sido destacado por la crítica especializada y que se desarrolla en distintas direcciones. La frecuentación del cancionero tradicional y popular deriva, como ya se ha dicho, en la asimilación del poema a la canción, que adquiere diversos matices en su obra y que facilita el

3 En 1958, León Felipe publicó, como prólogo a Belleza cruel (Figuera, 1958), un texto en el que ofrecía su reconocimiento a los poetas del interior de España, no solo a Ángela Figuera sino, a través de ella, también a otros como Celaya, Hierro, Crémer, etc. 
desarrollo de poemas inspirados en las formas musicadas de la lírica tradicional y popular, siempre considerando y teniendo en cuenta los matices que operan en estos dos conceptos. Me valdré de la síntesis de Maryse Bertrand de Muñoz para traerlas aquí de forma tan sucinta como clara (2009: 16):

Ya en 1927, Eduardo López Chavarri había definido el verdadero sentido de la canción popular: "Cuando la emoción nos domina el alma, se vuelve canto, se vuelve música, y es por esa música por lo que llegamos a comprender el verdadero sentir de las cosas».Y más tarde Ramón Menéndez Pidal establecía claramente la diferencia entre la poesía "popular» y la «tradicional»: la primera la «que tiene méritos para agradar a todos en general, para ser repetida por muchos y perdurar en el gusto del público bastante tiempo» y la segunda es la "que se refunde en cada una de sus variantes» y concluye Menéndez Pidal que «la esencia de lo tradicional está, pues, más allá de la mera recepción o aceptación de una poesía por el pueblo [...] está en la reelaboración de la poesía por medio de las variantes».

\section{DIÁLOGO CON LA CANCIÓN TRADICIONAL Y POPULAR}

La distinción entre poesía tradicional y popular me da pie para recurrir a la exposición de dos líneas fundamentales que se asientan en la temática poética de José Agustín Goytisolo y que funden, en torno al concepto de canción, la tradición y la actualidad, derivando por momentos hacia el cancionero tradicional o hacia el cancionero popular contemporáneo. Empezaré, propiamente, por la canción tradicional, que, siendo una fuente primaria esencial en la obra del autor, ha sido minuciosamente atendida por sus principales estudiosos, como es el caso de Carme Riera, Ramón García Mateos y Jordi Virallonga.

El trabajo de García Mateos (2005) considera la relación de Goytisolo con la poesía popular - no solo con el cancionero, aunque sí preferentemente- estableciendo algunos puntos esenciales al respecto, que son: 1) que el acceso de Goytisolo a la poesía popular tuvo un origen experiencial y no libresco;2) que su vinculación con 
la poesía popular es temprana —él lo cifra en Claridad (1961) — y se asocia a la identificación del poeta con el pueblo llano;3) que son sus partidas de caza por tierras extremeñas lo que le proporciona un contacto directo con las fuentes populares de algunos de sus poemas, estudiando minuciosamente dichas fuentes en un conjunto de poemas pertenecientes, casi en su totalidad, a Los pasos del cazador.

Por su parte, JordiVirallonga (1992:31 y ss.) explora, entre otras cosas, los muchos motivos de la lírica popular que comparecen en la poesía de Goytisolo, tales como la caza de amor, la malmaridada, la mujer morena, etc.

En cuanto a Carme Riera, inserta el estudio de esta cuestión en la recuperación de la lírica tradicional por parte de los poetas contemporáneos. Es muy atinada la distinción que hace en su análisis entre popularismo y neopopularismo, catalogando a Goytisolo bajo el primer marbete, en tanto que adopta los rasgos líricos de la canción tradicional, no solo recreando sus motivos o mediante el diálogo intertextual. Para Riera, Goytisolo estaría en la tradición del popularismo - como Machado- en tanto que adopta los rasgos líricos de la canción tradicional, desdeñando las florituras estilísticas añadidas a esta en «las reelaboraciones de los poetas del Siglo de Oro». Un apunte de Riera que considero esencial es el que nos advierte de que «[1]os rasgos estilísticos que caracterizan a la canción lírica tradicional más genuina, simplicidad máxima y máxima intensidad, conseguidos casi siempre a base de la reiteración de unos elementos mínimos, estaban en consonancia, además, con la voluntad de los poetas comprometidos de desdeñar la retórica y acudir a la repetición como rasgo configurador del estilo» (1991: 98-99).

Como muestra representativa de la simbiosis intertextual entre la obra de Goytisolo y el cancionero popular, podría mencionarse la "Canción del no se va», basada en una obra del cancionero asturleonés titulada «No se va la paloma». Es, fundamentalmente, una canción de despedida, un texto de apego a las raíces e interiorización de los afectos, cuyo estribillo reproduce el poema de Goytisolo, en un entorno semántico que apunta específicamente a la temática amorosa. El amor se expresa en términos de entrega del conjunto de bienes inmateriales que los amantes se ofrecen en exclusiva y en términos de posesión, en tanto que es esa exclusividad de la entrega lo que se asume como instrumento para retener a la otra persona. 
De este poema, siguiendo la edición de la poesía goytisoliana hecha por Carme Riera y Ramón García Mateos (2009), existen tres versiones en las que se percibe la evolución de la temática general antes expuesta. En la versión primera, la de 1968, se incide en la exclusividad de la comunicación, la entrega a la otra persona de un conocimiento de lo más privado de la identidad personal. Se habla también de una entrega sin contrapartida material — «le diré lo que a otras / no digo por dinero" - y se pone de manifiesto el vértigo de una entrega absoluta. La última versión, de 1996, matiza algunas cosas: concreta los bienes inmateriales transmisibles - gozo, sombras, sueños - y enuncia con más claridad el vértigo de la entrega, refiriéndose expresamente al amor: «A quien yo bien conozco / le haré ver lo terrible / que es el amor más hondo» (Goytisolo, 2009: 153). Ha señalado Riera que el motivo de la paloma enlaza este poema tanto con la tradición popular como con la tradición culta. Respecto a la tradición culta, recoge el motivo de la paloma de Alberti en el conocido poema «Se equivocó la paloma» (Riera, 1991: 105). La paloma sería en un caso la emisaria y en otro la representación del amor. En cuanto a la tradición popular, recuerda, además de la canción tradicional, el título de una canción popular cantada por tonadilleras como Marifé de Triana o Concha Piquer, titulada «No se va la paloma», cuya letra refiere la historia de una adúltera que se arrepiente para volver al nido y a la crianza de sus polluelos. Las reminiscencias, pues, se entrecruzan en el poema desde distintos ámbitos.

Siendo mucha la presencia de los motivos propios del cancionero tradicional en la obra poética de Goytisolo, coincido con Carme Riera en que la huella principal y más persistente es la de sus rasgos formales, una y otra vez reelaborados en distintas composiciones, tratando de vincularse a la voz del pueblo, dando arraigo en su poesía a las requisitorias de la colectividad. Es justamente esta intersección uno de los aspectos más relevantes del tema. Valga, también como muestra, el poema IX de Los pasos del cazador, donde la simplicidad, la reiteración estructural y la economía de medios apuntan claramente a la influencia popular (Goytisolo, 2009: 381):

\author{
Yo canto \\ entre los racimos \\ porque me gusta \\ ese sitio.
}


Y canto

porque me escuchen

los que vendimian

conmigo.

Nadie canta

en Almadén

solo yo

y sé bien por qué.

Este poema es, además, una muestra del modo en que Goytisolo asocia la fusión del poeta con la voz de un colectivo que reivindica sus derechos y ambas cosas, a su vez, con la lírica tradicional.Aunque el poema se exprese en primera persona y hable de la realización personal del cantor, la última estrofa tiene claramente una intención política. Almadén, la localidad mencionada, es un municipio de la provincia de Ciudad Real mundialmente conocido por sus minas de mercurio. Aunque sin duda Goytisolo conocería el lugar con ocasión de alguna montería a la que asistiera — la caza es una de las tradiciones locales más arraigadas-, la situación socioeconómica de la minería y las constantes transformaciones en la extracción del mercurio para adaptarse al mercado internacional están en el fondo del poema.

\section{LAS NANAS}

No quisiera pasar por alto en este recorrido la canción de cuna, una sección de la canción popular con personalidad propia y cuya presencia en la poesía de este autor es más que ocasional.

En su modalidad más convencional, las nanas expresan la íntima comunicación entre madre e hijo, para calmar su llanto, tranquilizarle y adormecerle. Es en esta línea donde tendría cabida la definición de Gabriela Mistral, quien considera la canción de cuna como «un coloquio diurno y nocturno de la madre con su alma, con su hijo y con la Gea visible de día y audible de noche» (Mistral en Villamuza, 2004: 106). No deja de ser curioso que, como creación primordialmente femenina, las nanas tradicionales hayan tenido especiales problemas de conservación a lo largo del tiempo. Así lo ha visto Riera: «No cabe duda de que las nanas o canciones de cuna 
son una forma poética ligada a la tradición lírica que se transmite de manera oral, relacionadas con las llamadas canciones de los trabajos y los días, de las que tenemos muestras más antiguas que de las nanas. Tal vez porque, hasta que los poetas cultos se deciden a componerlas, son las mujeres quienes las crean y como creaciones femeninas dificilmente abandonan el ámbito doméstico» (Riera en León y Riera, 2010: X).

Goytisolo se sitúa, precisamente, en ese ámbito del poeta culto que recrea los motivos y el espíritu de las nanas, en el que han participado autores como Lorca,Alberti, Mistral, Fuertes, etc., y, al igual que han hecho otros, modifica sustancialmente el modelo tradicional.

Quizá la más cercana al patrón convencional es «La nana de Julia». Se trata de un poema que tiene por finalidad adormecer a una niña de corta edad. La inducción al sueño representa la temática esencial del poema. El sistema estrófico alterna secuencias de tres versos y secuencias de dos. Las secuencias de tres versos evocan la copla de pie quebrado, aunque difieren de la manriqueña en que el tercer verso no es tetrasílabo sino hexasílabo. Hexasílabos son también los pareados con los que se alternan los tercetos. Como rasgos asociados a la poesía popular se observan, por supuesto, el arte menor en la extensión del verso y las distintas formas de repetición verbal en que se soporta la estructura del poema, que vuelca, en un ritmo suave y repetitivo, el arrullo de la criatura que se pretende adormecer. A diferencia de la nana tradicional, sin embargo, cuya emisión se atribuye habitualmente a una voz femenina, aquí es la voz del padre la que acuna a la criatura. En el poema, la fluencia de los elementos acuático y aéreo — «[1]os niños van por la tierra / y las niñas por el aire; [1]os niños van por la orilla / y las niñas por el agua» (Goytisolo, 2009:114) — aporta una idea de continuidad que, como el sueño, arropa y conduce a la criatura al descanso. Pero la lógica del discurso se supedita al ritmo y a los recursos iterativos. Se adivina una mediavoz induciendo el sueño de la niña.

Distinto es el poema X de Los pasos del cazador, de 1980, que no tiene tanto la intención de adormecer a la criatura como la de ofrecerle consuelo en un momento de disgusto: «El pelele mi niño / se ha peleado / por una rebanada / de pan pringado» (Goytisolo, 2009:382). Este poema corresponde a una tipología diferente, puesto que, como se ha escrito, 
conviene diferenciar entre la nana que se canta al niño recién nacido y la que se canta al niño que ya anda y que empieza a hablar: con la primera se entretiene al infante con el esbozo melódico de la canción, dicha entre dientes y dándole más importancia al ritmo físico del balanceo que a la propia letra de la nana; con la segunda, cuyo destinatario es un niño un poco mayor que el anterior, lo que dice la nana tiene más importancia, pues el chico ya puede conocer el significado de muchas palabras y puede, por tanto, entender la exhortación $o$, incluso, la amenaza que, en ocasiones, se le transmite con el canto de la nana (Cerrillo, 2010: en línea).

Otras nanas constituyen, claramente, una reescritura del género, como es frecuente en la poesía culta. Las de Goytisolo tienen en común el hecho de tener figuras centrales femeninas. En su mayor parte, por lo demás, se dirigen a mujeres adultas. Así, «Non non» (2009: 364) ofrece consejos a una mujer para derrotar al insomnio. El poema relaciona la falta de sueño con la angustia vital, con la carga de la propia existencia, que hay que aprender a relativizar para dominarla.

Reseñable es también la "Nana de la adúltera», que entronca desde distintas perspectivas con la canción tradicional, tanto por el tema mismo de la mujer adúltera, como por la referencia al personaje fantástico del "papón», como por la reescritura de una canción de cuna asturiana, la que dice: «El que está en la puerta / que non entre agora, / que está el padre en casa / del ñeñu que llora. / Ea, mi neñín, agora non, / ea, mi neñín que está el papón».

En este poema es la mujer quien habla, suplicando al amante que aplace su visita hasta que el marido salga de casa, recordándole al amante la amenaza del "papón». Este personaje, como el coco, el sacamantecas, el hombre del saco, etc., es un personaje imaginario al que se invoca para asustar a los niños, se trata de una de esos engendros que suelen aparecer en las nanas tradicionales; pero la figura del «papón» tiene también, tanto en el poema de Goytisolo como en la nana que lo inspira, el valor adicional de su similitud fonética con «papá», lo que asocia la figura del progenitor a la del personaje asustador. El miedo de la mujer a ser descubierta en su infidelidad sube de grado con la adición de una tercera estrofa, situada en el medio del poema, donde el marido se describe como militar: «El padre se viste / para ir al cuartel. / Padre amante y niño / me matáis 
los tres. / Ahora no / ahora no / ahora no amor mío / ahora no» (Goytisolo, 2009: 365). Como se ve en la estrofa anterior, la mujer se muestra debilitada por las exigencias simultáneas de tres varones, uno de los cuales satiriza a un militar que encarna los valores de la etapa dictatorial ya clausurada.

Muy tierno es el poema XXXV de Los pasos del cazador, una nana a su perra de caza a la que imagina soñando con zorros, igual que el sueño plácido de los niños se representa como «soñar con los angelitos»: «Dormida está mi perra / junto al rescoldo / dormida y calentita / soñando en zorros. // Ea ea ea / mi perra no es fea». Celaya primero (1975) y después León y Riera (2010) recogen en sus respectivas selecciones antológicas una nana que inspira el estribillo de esta: «Ea, ea, ea / que la niña no es tan fea / y si lo es, que lo sea, / ea, ea, ea».

Quiero también referirme, para acabar este apartado, a «Tu luz sea leve» (Goytisolo, 2009: 463), una canción de cuna dedicada a una niña - no importa de qué edad - cuyo sueño, arropado por la luz de la luna, se quiere preservar. Su delicado lirismo contrasta con el desenfado y la sátira de las anteriores: «Noche que tan clara esplendes / tu luz sea leve. // No despiertes a la niña / que está dormida. // Haz que tu fulgor ya cese / noche que esplendes».

\section{CANCIONES POPULARES CONTEMPORÁNEAS}

Las fuentes cancioneriles no se agotan en el venero tradicional, siendo necesario reconocer que la canción popular contemporánea, abarcando muy diversos géneros, es también un semillero fecundo para la poesía de José Agustín Goytisolo. Me centraré únicamente en un breve conjunto de muestras para reflejarlo.

El primer poema al que quiero referirme se titula «Bárbara» y tiene como hipotexto un poema homónimo de Jacques Prévert que fue musicado por Joseph Kosma en 1947. El texto apela a una joven desconocida a la que un día vio corriendo, feliz, en un día lluvioso, hacia los brazos de un hombre. Sobre esta escena feliz se superponen los días posteriores de guerra, su lluvia de fuego y metralla, que encierran la felicidad en un lejano recuerdo. La ciudad de Brest, sobre la que cae, primero, la lluvia climática y luego, la lluvia incesante de 
bombas, es el escenario de los acontecimientos que Prévert quiere fijar en su poema. Brest, situada al oeste en la Bretaña francesa, fue un enclave estratégico durante la segunda guerra mundial. Ocupada por los nazis, que la utilizaron como base submarina, quedó completamente arrasada tras la guerra. Los aliados bombardearon la ciudad en 165 ocasiones, para expulsar a los nazis, entre 1940 y 1944. El poema, obviamente escrito en el entorno moral y político de ese conflicto, deja implícita la separación definitiva de los amantes, indicando que la destrucción de la guerra alcanza a todos los rincones de la ciudad y también al espíritu y la memoria de sus habitantes.

La Bárbara de Goytisolo aparece fuera de contexto, aunque este sobrevuela los inequívocos guiños a la canción: "Acuérdate», «Rappelle-toi», «Bárbara».

\title{
BÁRBARA
}

\author{
Acuérdate \\ cuenta las piedras una a una \\ dobla la esquina \\ entra al silencio de la calle \\ sigue derecho hasta tu casa \\ acuérdate \\ es poco antes de llegar \\ a la plazuela de la Iglesia \\ detente ahí \\ saca la llave del bolsillo \\ acuérdate \\ busca con tino el agujero \\ dale dos vueltas \\ empuja dentro sin temor \\ ponte a soñar \\ et rappelle toi (Goytisolo, 2009: 340).
}

El poema aparece en un libro titulado Del tiempo y del olvido (1977) que gira en torno al transcurso del tiempo y a la memoria que permite reconstruir, verbalizándola, una realidad que ya no existe. De hecho, en el poema solo queda la memoria: ni la lluvia, ni el hombre que abrazaba a Bárbara, ni la felicidad. Queda la mujer solitaria, abocada al recuerdo. Y queda también la voz que interpela - un rasgo común a la canción - y que empatiza con la mujer. Elidido queda el contexto histórico que el poema de Prévert, 
luego convertido en canción, aporta: no es necesario. El poema de Goytisolo se presenta como apéndice a una historia fragmentaria, quizás inconclusa.

En una línea similar, incidiendo en la interpretación de la Historia contemporánea, mencionaré asimismo el poema «Abril en Portugal» (Goytisolo, 2009: 362). El poema hace referencia en su título a un conocido fado portugués, popularizado por Amália Rodrigues, cuyo título original es "Coimbra». En traducción a otras lenguas la canción se divulgó como «Abril en Portugal» —o su equivalente— - y su letra consistía, esencialmente, en una exaltación saudosa de la tierra lusa. La intención de Goytisolo, como decía, avanza en otra dirección: «En Lisboa yo vi un clavel / cuyo nombre es el de Isabel / por las calles anda esa flor / y allí la llaman Revolución».

Con base en la canción mundialmente conocida, Goytisolo pone en primer plano los acontecimientos del 25 de abril de 1974 en Portugal, cuando varios oficiales del ejército, al mando del mayor Otelo Saraiva de Carvalho, se levantaron contra el régimen dictatorial de Marcelo Caetano — sucesor de Salazar- con el apoyo de numerosos civiles. En apenas veinticuatro horas y sin provocar derramamiento de sangre, el movimiento revolucionario se hizo con el control completo del país. Desde España, los sucesos del abril portugués de 1974 se vivieron con contenida emoción por parte de la ciudadanía, que deseaba fervientemente la llegada de la democracia a este país.

Goytisolo feminiza la revolución como una mujer seductora y deseada, pero también frágil y vulnerable, como lo era la revolución portuguesa. Hay indudablemente un correlato objetivo en el poema, de evidente intención política. La codiciada mujer del texto, escrito en la atmósfera política promovida por el caso portugués, simboliza el deseo de la llegada de la democracia a España, por una vía igualmente pacífica.

Y, junto a los ejemplos anteriores, que destacan el compromiso político goytisoliano, podrían citarse igualmente poemas de contenido más personal. "Como tango» (Goytisolo, 2009: 470), incluido primero en Claridad (1961) y, luego, en $A$ veces gran amor (1981), sería un ejemplo.

Los sones del tango tienen reverberaciones en la literatura española. Ramón Gómez de la Serna lo conoció intensamente en 
su exilio argentino y escribió sobre él (1949). También a Federico García Lorca, que visitó Argentina en 1933, le interesó mucho el tango. En esa visita conoció a Gardel y, posteriormente, llegó a acompañar al matrimonio Discépolo en su viaje por España. Quizá este antecedente influyó en el interés por el tango que manifestaron en su etapa inicial los poetas de «la otra sentimentalidad». En el bar La tertulia, regentado por el argentino Horacio Rébora, tuvieron su cuartel general los fundadores de este grupo poético y allí conocieron y disfrutaron en profundidad del tango (Valverde, 2010: en línea).

Goytisolo escribió este poema mucho antes de asistir a La tertulia en compañía de los jóvenes poetas granadinos, mucho antes que se fundara ese bar, antes incluso de que Gil de Biedma publicara aquellas definitivas palabras de «El juego de hacer versos»: «la mejor poesía / es elVerbo hecho tango» (Gil de Biedma, 1985: 76).

Sin duda el tono de Gil de Biedma y el de Goytisolo difieren. Gil de Biedma utiliza su característica sorna para definir la poesía como una simbiosis entre la palabra sagrada y un género arrabalero, urbano y marginal por excelencia, que canta la tragedia de la vida. Goytisolo, en cambio, escribe, en verdad, un tango de esos que reflejan el dolor de la experiencia.

«Se ha dicho que todos los tangos son el mismo tango - escribe Antoni Pau-. Que cada pieza es un fragmento de una misma queja. Que el hombre abandonado sigue apoyado en la misma esquina, y sigue doliéndose de los mismos agravios y de la misma herida.Y es verdad. Ese personaje del tango, que habla siempre en primera persona, no canta para desahogarse y olvidar, sino para enconarse y revivir» (Pau Pedrón, 2001: 23). En el caso de Goytisolo, la herida de la que habla Pau tiene los mismos nombres que en «Llegó con tres heridas», el famoso poema de Hernández: vida, amor y muerte (1992: 694). Tiene los bordes de la experiencia cotidiana, su luminosidad y su desgarro. El cantor habla consigo mismo, con su corazón desbocado por los golpes de la vida, pidiendo una tregua en la batalla constante.

Por último, para cerrar esta sección, quiero referirme a «Bolero para Jaime Gil de Biedma» (Goytisolo, 2009: 230), de Bajo tolerancia. Como es sabido, el bolero es un género sentimental y melancólico y, aunque sus letras suelen ser de temática amorosa, el poema de Goytisolo se ciñe al carácter taciturno de este tipo de composiciones para enviarle a su amigo un mensaje de comprensión y solidaridad 
ante el sentimiento de pérdida que se trasluce en determinados poemas biedmianos evocadores de una arcadia anterior al despertar de la conciencia crítica que ha desarrollado de adulto. Esa conciencia es la protagonista de la segunda estrofa, y se presenta como una carga para la persona que, en circunstancias adversas, desarrolla un pensamiento libre e independiente.

\section{COLOFÓN}

Los aspectos que he desarrollado entre poesía y canción en la obra de José Agustín Goytisolo, así como los ejemplos con los que he representado lo que a todas luces es una fuerte simbiosis, pretenden ser, únicamente, una aproximación al tema. Una lectura sistemática de esta obra pone de manifiesto que el asunto se expande en todas direcciones a lo largo de la misma. Entre sus muchas ramificaciones, la canción aparece conceptuada como representación del alma humana individual, como espíritu coral del mundo, como armonía o amor - en un plano individual o colectivo-, como liberadora del espíritu. Todo ello debe, también, entenderse en un sentido metapoético. Así lo pone de relieve el autor en numerosas ocasiones. Por ejemplo, en el poema «En tiempos de ignominia» (Goytisolo, 2009: 841):

En tiempos de ignominia como ahora

a escala planetaria, y cuando la crueldad se extiende por doquier fría y robotizada, aún queda buena gente en este mundo que escucha una canción o lee un poema: es el canto la voz y la palabra: única patria que no pueden robarnos ni aun poniéndonos de espaldas contra el muro.

Sobre la conocida pregunta de Hölderlin — «Para qué poetas en tiempos de miseria?»— Goytisolo desgrana su personal respuesta: la poesía representa la defensa de un patrimonio inmaterial que fomenta la resistencia contra las agresiones del presente histórico. El canto goytisoliano conserva su sesgo testimonial a través de los años, incluso pasado su período de vigencia frente a la dictadura franquista, como escribe en el poema-epílogo a su obra completa: 
«Tú tomaste partido por la vida / que se les niega a los desheredados. / Comprendo que te hiera este dolor / pero no llores: canta. Tu mejor testimonio / es una voz al aire y no el gran ruido / que no permite hablar» (Goytisolo, 2009: 842). Llega un día en que la protesta se adapta a un modelo de tono mesurado, que descarta la ira y abraza la ternura, pero no baja la guardia.Y no lo hace porque Goytisolo ha vinculado su identidad personal a esa voz que el aire dispersa, sin la que no sería capaz de entender el mundo, ni siquiera de entenderse a sí mismo. Un poema de Cuaderno del Escorial — «La alegría se llama canción» (Goytisolo, 2009: 759)— dice así: «En todos los lugares que escuché tu tonada / recobré la alegría; la pasión de vivir. / Canción que yo esperaba salieras de mi pluma / resultó que tú fuiste la que se adentró en mí». Esta interiorización de la poesía, como rasgo identitario profundo, es el fragmento más significativo de un poema donde música y poesía se equiparan en la capacidad para generar emociones. El poeta es fiel a su línea de colocar en un segundo plano el virtuosismo literario y la memoria misma del autor. Lo que importa de la poesía, en última instancia, es su capacidad para transformar la experiencia del ser humano, de quien la recibe, por supuesto, pero también de quien la escribe, convertido él mismo en materia del canto. 


\section{BIBLIOGRAFÍA}

Barjau Riu, Eustaquio (2009). «Goethe en la historia del lied alemán», Quodlibet. Revista de Especialización Musical, 44, pp. 42-55.

Bertrand de Muñoz, Maryse (ed.) (2009). Si me quieres escribir. Canciones políticas y de combate de la guerra de España, Madrid, Calambur.

CÁrdenas, José C. (2017a). «José Agustín Goytisolo y su relación con la música. Primera parte», http:// cancionypoema.blogspot. com/search?updated-max=2017-01-30T12:09:00-08:00\&maxresults $=20 \&$ start $=25 \&$ by-date $=$ false. Consultado el 26 de junio de 2019.

— (2017b). «José Agustín Goytisolo y su relación con la música. Parte II», https://cancionypoema.blogspot.com/2017/01/jose-agustin-goytisoloy-su-relacion_30.html. Consultado el 26 de junio de 2019.

(2017c). «José Agustín Goytisolo y su relación con la música. Parte III», http:// cancionypoema.blogspot.com/search?updated-max=2017-02-25T12:39:0008:00\&max-results $=20 \&$ start $=23 \&$ by-date $=$ false. Consultado el 26 de junio de 2019 . — (2017d). «José Agustín Goytisolo y su relación con la música. Parte IV», http:// cancionypoema.blogspot.com/search?updated-max=2017-03-06T11:51:0008:00\&max-results $=20 \&$ start $=22 \&$ by-date $=$ false. Consultado el 26 de junio de 2019 . — (2017e). «José Agustín Goytisolo y su relación con la música. Parte V», http:// cancionypoema.blogspot.com/search?updated-max=2017-03-14T09:39:0007:00\&max-results $=20 \&$ start $=21 \&$ by-date $=$ false. Consultado el 26 de junio de 2019 .

— (2017f). «osé Agustín Goytisolo y su relación con la música. Parte VI», http://cancionypoema.blogspot.com/search/label/0\%20JOS\%C3\%89\%20 AGUST\%C3\%8DN\%20GOYTISOLO. Consultado el 26 de junio de 2019.

Celaya, Gabriel (1975). La voz de los niños, Barcelona, Laia.

Cerrillo Torremocha, Pedro César (2010). «Amor y miedo en las nanas de tradición hispánica», http://www.cervantesvirtual.com/obra-visor/amory-miedo-en-las-nanas-de-tradicion-hispanica/html/4d2ceae0-6bf0-4413a79d-72bc6d2c5a40_2.html. Consultado el 10 de agosto de 2019.

Figuera, Ángela (1958). Belleza cruel, México, Compañía General de Ediciones. García Mateos, Ramón (2005). «Poesía popular-poesía culta: los cantes de ida y vuelta. El ejemplo de José Agustín Goytisolo», Actas del I Simposio internacional José Agustín Goytisolo, Palma de Mallorca, Universitat de les Illes Balears, pp. 99-115. Gil De Biedma, Jaime (1985 [1966]). Moralidades, Barcelona, Taifa. 
Gómez de la Serna, Ramón (1949). Interpretación del tango, Santa Fe (Argentina), Ultreya. Goytisolo, José Agustín (1980). Palabras para Julia y otras canciones, Barcelona, Laia.

— (2009). Poesía completa, ed. Carme Riera y Ramón García Mateos, Madrid, Lumen. Hernández, Miguel (1992). Obra completa, ed. Agustín SánchezVidal y José Carlos Rovira, con la colaboración de Carmen Alemany, Madrid, Espasa-Calpe, vol. I. León Felipe (2006 [1943]). Ganarás la luz, ed. José Paulino Ayuso, Madrid, Cátedra. LeÓn, Araceli y Carme Riera (2010). El gran libro de las nanas, Barcelona, El Aleph. Pau Pedrón, Antoni (2001). Música y poesía del tango, Madrid, Trotta.

Riera, Carme (1991). Hay veneno y jazmín en tu tinta. Aproximación a la poesía de J. A. Goytisolo, Barcelona, Anthropos.

SOURIAU, Etienne (1969). La correspondance des arts. Eléments d'esthétique comparée, Paris, Flammarion.

Valverde, Fernando (2010). «Alberti y su bar granadino», El País, 1 de marzo, https://elpais.com/diario/2010/03/01/ andalucia/1267399330_850215.html. Consultado el 21/7/2019.

VÁzQuez Montalbán, Manuel (1980). «Goytisolo, un poeta de perfil», en José Agustín Goytisolo, Palabras para Julia y otras canciones, Barcelona, Lumen, pp. 6-8.

Villamuza, Noemí (2004). Libro de nanas, Valencia, Media Vaca.

Virallonga, Jordi (1992). José Agustín Goytisolo. Vida y obra, Madrid, Libertarias/Prodhufi. 